\title{
Effects of hallux valgus angle on one-legged stance and gait parameters in young adults: a preliminary study
}

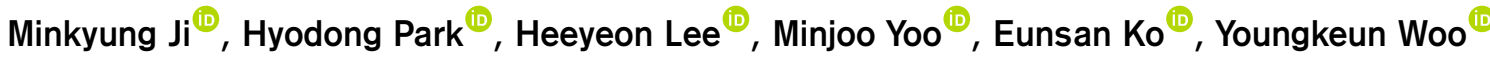 \\ Department of Physical Therapy, College of Medical Sciences, Jeonju University, Jeonju, Republic of Korea
}

Objective: Hallux valgus (HV) is a common musculoskeletal deformity that is accompanied with pain and continues to decrease one's quality of life and ability to perform daily life activities by affecting gait and static stability. Therefore, this study aimed to investigate the effect of the angle of HV (HVA) and to compare the one-legged stance and gait parameters in young adults with less HV and severe HV.

Design: Cross-sectional study.

Methods: Forty young adults were divided into two groups, where $\mathrm{HVA} \geq 15^{\circ}(\mathrm{n}=20)$ was defined as $\mathrm{HV}$, and $\mathrm{HVA}<15^{\circ}$ ( $\mathrm{n}=20$ ) was defined as normal. For balance ability, the center of pressure (COP) path, velocity, length of axis of the COP path, deviation of the $\mathrm{x}$-axis and $\mathrm{y}$-axis, and percentage of foot pressure were measured, and gait, the foot rotation angle, step length, percentage of each phase of the gait cycle, time change from the heel to forefoot, and maximum pressure of the forefoot and midfoot were measured. Results: Significant differences were found in sway length and time change from heel to forefoot during walking between the normal and HV groups $(p<0.05)$. Most parameters were not associated with the HVA, but parameters such as length of axis and time to change from heel to forefoot were significantly associated with the HVA $(p<0.05)$.

Conclusions: These results suggest that most one-legged stance and gait parameters were not significantly affected by the HVA in young adults; therefore, future studies are needed in order to address other dynamic parameters and other methods of gait analysis for detecting clinically meaningful conditions.

Key Words: Balance; Gait; Hallux valgus

\section{Introduction}

Hallux valgus (HV) is one of the most common foot deformities requiring orthopedic care [1]. It is characterized as a lateral deformity of the extensor and flexor tendons of the big toe with a medial deviation of the first metatarsal head and a lateral deviation of the proximal phalanx of the hallux, which occurs because the medial collateral ligament and joint capsule become attenuated [2]. The reported prevalence of HV were $28.4 \%$ in young adults [3] and as high as $74 \%$ in older adults [4]. HV is more common in female and elderly individuals, and the latter group has an increased risk for falls [5].
In general, $\mathrm{HV}$ is diagnosed by measuring the angle between the first metatarsal and the hallux, the angle between the first and second metatarsals, and the distal metatarsal articular angle [6,7]. In radiographic measurements, a normal $\mathrm{HV}$ angle (HVA) is $\leq 15$, and the first to second intermetatarsal angle is $\leq 8^{\circ}-9^{\circ}$ [8]. Pique-Vidal and Vila [9] classified HV deformities into normal $\left(<15^{\circ}\right)$, mild $\left(15^{\circ}\right.$ $\left.20^{\circ}\right)$, moderate $\left(21^{\circ}-39^{\circ}\right)$, and severe $\left(\geq 40^{\circ}\right)$ based on the HVA.

$\mathrm{HV}$ is characterized by pain, impaired balance, deformities of the lower limbs, and movement disorder related to lower limb kinetics, leading to a reduction of physical activity [10]. In addition, HV is distinguished by a greater reduc-

Received: 11 March, 2020 Revised: 24 March, 2020 Accepted: 24 March, 2020

Corresponding author: Youngkeun Woo (ORCID https://orcid.org/0000-0003-4360-7390)

Department of Physical Therapy, College of Medical Sciences, Jeonju University, 303 Cheonjam-ro, Wansan-gu, Jeonju 56069, Republic of Korea Tel: 82-63-220-3163 Fax: 82-63-220-2054 E-mail: ykwoo92@empas.com

(c) This is an Open-Access article distributed under the terms of the Creative Commons Attribution Non-Commercial License (http://creativecommons.org/licenses/ by-nc/4.0) which permits unrestricted non-commercial use, distribution, and reproduction in any medium, provided the original work is properly cited.

Copyright ( 2020 Korean Academy of Physical Therapy Rehabilitation Science 
tion in the size of the abductor hallucis compared with the normal hallux [10] and/or by the collapse of the arch [2]. Suzuki et al. [11] claimed that HV can be accompanied with pain in the metatarsal and medial metatarsal arch collapse in the static position. Individuals with HV have to bear loads caused by different lower extremity alignment compared with healthy individuals, which affects their walking ability [12]. Deschamps et al. [1] reported a significant difference in heel abduction angles during walking between HV and normal groups and that such a change can affect postural stability and balance. Wen et al. [13] reported a decreased single-leg stance performance in young adults who had HV that caused no pain and stated that HVA can potentially cause injury by deteriorating their single-leg stance performance during sports activities. According to Nishimura et al. [14], HV deformities with an HVA greater than $30^{\circ}$ decrease one's maximum walking speed, and painful HV negatively affects general gait features, including maximum walking speed. Plantar pressure is also decreased to varying degrees, depending on the severity of HVA, and it is significantly lower in individuals with painful HA.

The first metatarsal joint acts as a pivot for transferring weight during the latter part of the stance phase of gait [15], and the force generation capacity of the plantar flexors in the first metatarsal is reduced because of the lateral deviation of the big toe [2,16]. Martinez-Nova et al. [17] reported no significant difference in the peak pressure between $\mathrm{HV}$ and control groups, whereas Bryant et al. [18] and Mickle et al. [19] asserted that the peak pressure increased, depending on the first and second metatarsal heads in individuals with severe HA compared with the control group.

The present study aimed to investigate the effect of the HVA on one-legged stance and gait abilities and to compare between young adults with less HV and severe HV.

\section{Methods}

\section{Study subjects}

This cross-sectional study included 40 young adults (6 men and 34 women) who had no pain in their lower extremities, including the hip and knee, and received no surgical treatment or physical therapy interventions to the lower extremities. Their weight, height, and HVAs from the left and right feet were measured, and demographic data such as age were collected. In this study, subjects were divided into the HV and normal groups based on HVA. When measured in the standing position, $\mathrm{HVA} \geq 15^{\circ}$ was defined as $\mathrm{HV}$
[16], and $\mathrm{HVA}<15^{\circ}$ was defined as normal [9]. All subjects were right-foot dominant. During the experiments, those who complained of lower limb pain and those who did not want to disclose their measurements were excluded from the analysis. The present study was approved by a local institutional review board (approval number: jjIRB-180713-HR2018-0708), and written informed consent form was obtained from each participant.

\section{Measurement instruments and methods}

\section{HVA measurement with a goniometer}

The goniometer $(36 \times 4.5 \mathrm{~cm})$ has an axis in the center to facilitate $360^{\circ}$ rotation, and it was used to measure the HVA. While subjects were standing in their normal stance, the axis of the goniometer was placed on the first metatarsal joint, with the stationary arm being aligned with the first metatarsal and the moving arm being aligned with the great toe to measure HVA in accordance with the guidelines published by the Ad Hoc Committee of the American Orthopedic Foot \& Ankle Society [20].

\section{Evaluation of unipedal balance and gait performance}

The subjects' one-legged stance and gait performance was measured with the Zebris-FDM 1.5 (Zebris Medical $\mathrm{GmbH}$, Isny, Germany). With dimensions of $580 \times 605 \times 21$ $\mathrm{mm}$ (length $\times$ width $\times$ height), this pressure distribution measurement system is used to measure balance and gait parameters with 11,264 force sensors, which record data at a sampling rate of $120 \mathrm{~Hz}$ per 1 second. To measure balance during the one-legged stance, the subjects were asked to alternate standing on their right and left legs for 30 seconds each and were allowed to rest for 1 minute. All measurements were repeated three times, and the average of the three scores was used in the analysis. For the one-legged stance, subjects were asked to cross the lifted foot behind the back of the other foot and place it on the crook of the standing knee with their arms placed on their hips. While tests were conducted bilaterally, the order of the test leg was determined via coin toss. For balance ability, the center of pressure (COP) path, velocity, length of axis of the COP path, deviation of the $\mathrm{x}$-axis and $\mathrm{y}$-axis, and percentage of foot pressure were measured.

For gait measurements, two units of the Zebris-FDM 1.5 were combined to make a 3-m-long measuring plate to which an additional $1.5-\mathrm{m}$ track was connected to make the start and end points. Subjects performed a 6-m walk test. At each measurement, the subjects were asked to look straight 
ahead to avoid potential visual biases. The test was repeated three times, and the average of the three scores was used in the analysis. For gait ability, the foot rotation angle, step length, percentage of each phase of the gait cycle, time change from the heel to forefoot, and maximum pressure of the forefoot and midfoot were measured.

\section{Statistical analysis}

Statistical analysis was performed using IBM SPSS Statistics for Windows, Version 25.0 (IBM Co., Armonk, NY, USA). An independent t-test was used to compare the differences in age, height, weight, and HVA between the groups. The non-parametric Mann-Whitney U-test was used to determine the differences in balance and gait parameters between the groups. To determine the relationship of HVA with parameters related to one-legged stance and gait performance, a simple regression analysis was performed using HVA as an independent variable and balance and gait parameters as dependent variables. Statistically significance level $\alpha$ was set to 0.05 .

\section{Results}

\section{General characteristics}

General characteristics of participants are shown in Table 1.

\section{Unipedal balance test on the left foot}

The results of the unipedal balance test on the left foot in the HV and normal groups are presented in Table 2. The length of the major and minor axes significantly increased in

Table 1. General characteristics of participants

$(\mathrm{N}=40)$

\begin{tabular}{clcrr}
\hline Side of foot & \multicolumn{1}{c}{ Parameters } & Normal adults $(\mathrm{n}=20)$ & HV adults $(\mathrm{n}=20)$ & $\mathrm{t}(p)$ \\
\hline Left $(\mathrm{n}=20)$ & Age $(\mathrm{y})$ & $21.85(1.18)$ & $20.70(1.17)$ & $3.807(0.004)$ \\
& Height $(\mathrm{cm})$ & $164.29(7.86)$ & $165.17(8.72)$ & $-0.335(0.739)$ \\
& Weight $(\mathrm{kg})$ & $58.10(10.23)$ & $62.05(9.83)$ & $-1.245(0.221)$ \\
& Angle of $\mathrm{HV}\left({ }^{\circ}\right)$ & $10.95(2.72)$ & $23.85(5.05)$ & $-10.055(<0.001)$ \\
Right $(\mathrm{n}=20)$ & Age $(\mathrm{y})$ & $21.80(1.24)$ & $20.75(1.16)$ & $2.761(0.009)$ \\
& Height $(\mathrm{cm})$ & $164.64(7.75)$ & $62.82(8.84)$ & $-0.068(0.946)$ \\
& Weight $(\mathrm{kg})$ & $58.05(10.21)$ & $22.00(4.96)$ & $-1.278(0.209)$ \\
& Angle of $\mathrm{HV}\left({ }^{\circ}\right)$ & $10.30(3.67)$ & & $-8.475(<0.001)$ \\
\hline
\end{tabular}

Values are presented as mean (SD).

HV: halux valgus.

Table 2. Parameters during left one-leg stance balance between normal adults and HV adults

\begin{tabular}{lcrc}
\hline \multicolumn{1}{c}{ Parameters } & Normal adults $(\mathrm{n}=20)$ & HV adults $(\mathrm{n}=20)$ & $\mathrm{Z}(p)$ \\
\hline Forefoot COP X (mm) & $-48.58(44.20)$ & $-50.75(38.54)$ & $-0.487(0.626)$ \\
Forefoot COP Y (mm) & $59.58(31.63)$ & $60.95(26.57)$ & $-0.703(0.482)$ \\
Backfoot COP X (mm) & $-23.48(24.40)$ & $-36.52(32.60)$ & $-1.488(0.137)$ \\
Backfoot COP Y (mm) & $-44.39(13.01)$ & $-48.09(12.83)$ & $-0.866(0.387)$ \\
COP X (mm) & $-25.17(51.41)$ & $-32.46(38.30)$ & $-0.730(0.465)$ \\
COP Y (mm) & $21.11(40.94)$ & $12.60(35.73)$ & $-1.082(0.279)$ \\
COP path (mm) & $922.37(203.84)$ & $1235.20(622.40)$ & $-1.434(0.152)$ \\
COP velocity $(\mathrm{mm} / \mathrm{s})$ & $30.75(6.79)$ & $41.17(20.75)$ & $-1.434(0.152)$ \\
Length of minor axis (mm) & $24.59(4.29)$ & $30.92(9.54)$ & $-2.137(0.033)$ \\
Length of major axis $(\mathrm{mm})$ & $39.22(7.49)$ & $62.45(33.54)$ & $-2.570(0.010)$ \\
Angle between Y and major axis $\left(^{\circ}\right)$ & $18.38(10.62)$ & $14.84(11.55)$ & $-1.353(0.176)$ \\
Deviation X (mm) & $-25.16(51.41)$ & $-32.28(38.42)$ & $-0.676(0.499)$ \\
Deviation Y $(\mathrm{mm})$ & $21.09(40.93)$ & $12.65(35.98)$ & $-1.082(0.279)$ \\
Forefoot force $(\%)$ & $67.13(15.54)$ & $59.19(11.13)$ & $-2.056(0.040)$ \\
Backfoot force $(\%)$ & $31.20(13.54)$ & $39.14(12.23)$ & $-2.110(0.035)$ \\
Total force $(\%)$ & $60.51(16.67)$ & $66.57(17.19)$ & $-1.001(0.317)$ \\
\hline
\end{tabular}

Values are presented as mean (SD).

HV: halux valgus, COP: center of pressure. 
the HV group compared with the normal group $(p<0.05)$. The force $(\%)$ on the forefoot was significantly lower in the HV group than in the normal group $(p<0.05)$, whereas that on the back foot was significantly higher in the HV group than in the normal group $(p<0.05)$. However, there was no significant difference between the two groups with respect to other balance parameters.

\section{Unipedal balance test on the right foot}

The results of the unipedal balance test on the right foot in the HV and normal groups are presented in Table 3. The length of the major and minor axes significantly increased in the HV group compared with the normal group $(p<0.05)$. However, the other balance parameters were not significantly different between the groups.

\section{Evaluation of gait characteristics (left foot)}

The parameters derived from the analysis of the left foot while walking are summarized by group in Table 4 . The time change from the heel to forefoot, expressed in seconds and as a change in percentage, was significantly shorter in the HV group than in the normal group $(p<0.05)$. However, the other gait parameters were not significantly different between the groups.

\section{Evaluation of gait characteristics (right foot)}

The parameters derived from the analysis of the right foot while walking are summarized by group in Table 5 . The time change from the heel to forefoot, expressed as a change in percentage, was significantly shorter in the HV group than in the normal group $(p<0.05)$. However, the other gait parameters were not significantly different between the groups.

\section{Simple linear regression analysis}

A simple linear regression analysis was performed to determine the relationship of HVA with balance and gait parameters, and the results are summarized in Tables 6 (left foot) and 7 (right foot). In the linear regression models derived for gait parameters, the time change from the heel to forefoot, expressed in seconds and as a change in percentage, was significant in the left foot $(p<0.05)$. However, other left gait parameters did not show significant differences $(p<0.05)$. In the assessment of standing balance on the left foot, a statistically significant regression equation was derived for the major and minor axes $(p<0.05)$. The time change from the heel to forefoot, expressed as percent change, was also significant $(p<0.05)$ in the right foot. However, other gait parameters did not show significant differences. Additionally, other balance parameters measured while standing on the right foot were not statistically significantly different.

Table 3. Parameters during right one-leg stance balance between normal adults and HV adults

$(\mathrm{N}=40)$

\begin{tabular}{lccc}
\hline \multicolumn{1}{c}{ Parameters } & Normal adults $(\mathrm{n}=20)$ & HV adults $(\mathrm{n}=20)$ & $\mathrm{Z}(p)$ \\
\hline Forefoot COP X (mm) & $56.55(100.83)$ & $58.25(41.56)$ & $-1.758(0.079)$ \\
Forefoot COP Y (mm) & $47.64(21.92)$ & $69.36(40.48)$ & $-1.812(0.070)$ \\
Backfoot COP X (mm) & $49.57(100.44)$ & $35.92(26.14)$ & $-0.947(0.344)$ \\
Backfoot COP Y (mm) & $-32.44(12.52)$ & $-34.18(13.17)$ & $-0.784(0.433)$ \\
COP X (mm) & $33.53(104.39)$ & $38.58(51.68)$ & $-1.650(0.099)$ \\
COP Y (mm) & $7.62(27.06)$ & $33.36(53.30)$ & $-1.569(0.117)$ \\
COP path $(\mathrm{mm})$ & $1108.09(333.01)$ & $1326.58(443.75)$ & $-1.353(0.176)$ \\
COP velocity $(\mathrm{mm} / \mathrm{sec})$ & $36.94(11.10)$ & $44.22(14.79)$ & $-1.353(0.176)$ \\
Length of minor axis $(\mathrm{mm})$ & $28.38(7.47)$ & $33.77(7.16)$ & $-2.489(0.013)$ \\
Length of major axis $(\mathrm{mm})$ & $43.85(12.95)$ & $58.14(23.40)$ & $-2.110(0.035)$ \\
Angle between Y and major axis $\left({ }^{\circ}\right)$ & $18.38(12.45)$ & $23.14(16.94)$ & $-0.866(0.387)$ \\
Deviation X $(\mathrm{mm})$ & $33.41(104.44)$ & $38.47(51.68)$ & $-1.596(0.110)$ \\
Deviation Y $(\mathrm{mm})$ & $7.71(27.05)$ & $33.41(53.20)$ & $-1.569(0.117)$ \\
Forefoot force $(\%)$ & $67.19(20.89)$ & $67.92(20.61)$ & $-0.162(0.871)$ \\
Backfoot force $(\%)$ & $31.14(18.06)$ & $28.75(14.24)$ & $-0.406(0.685)$ \\
Total force $(\%)$ & $49.41(20.71)$ & $62.20(22.46)$ & $-1.867(0.062)$ \\
\hline
\end{tabular}

Values are presented as mean (SD).

HV: halux valgus, COP: center of pressure. 
Table 4. Parameters in left foot during gait between normal adults and HV adults $(\mathrm{N}=40)$

\begin{tabular}{lcrc}
\hline \multicolumn{1}{c}{ Parameters } & Normal adults $(\mathrm{n}=20)$ & HV adults $(\mathrm{n}=20)$ & $\mathrm{Z}(p)$ \\
\hline Foot rotation $\left({ }^{\circ}\right)$ & $5.16(4.53)$ & $6.58(4.49)$ & $-1.136(0.256)$ \\
Step length $(\mathrm{cm})$ & $61.24(7.74)$ & $59.82(3.56)$ & $-0.906(0.365)$ \\
Stance phase (\%) & $62.83(1.92)$ & $63.04(0.77)$ & $-0.785(0.433)$ \\
Load response (\%) & $12.91(1.87)$ & $12.98(1.45)$ & $-0.081(0.935)$ \\
Mid stance (\%) & $37.00(1.69)$ & $37.26(1.76)$ & $-0.839(0.402)$ \\
Pre-swing (\%) & $12.94(1.84)$ & $12.86(1.03)$ & $-0.257(0.797)$ \\
Swing phase $(\%)$ & $37.17(1.92)$ & $36.96(0.77)$ & $-0.785(0.433)$ \\
Step time $(\mathrm{s})$ & $0.53(0.05)$ & $0.53(0.04)$ & $-0.108(0.914)$ \\
Length of gait line (mm) & $215.63(12.95)$ & $209.41(19.71)$ & $-0.866(0.387)$ \\
Single support line (mm) & $116.94(9.48)$ & $114.55(6.77)$ & $-1.542(0.123)$ \\
Time change heel to forefoot $(\mathrm{s})$ & $0.28(0.05)$ & $0.25(0.05)$ & $-2.016(0.044)$ \\
Time change heel to forefoot $(\%)$ & $42.48(5.62)$ & $36.98(6.71)$ & $-3.003(0.003)$ \\
Maximum force of forefoot $(\mathrm{N})$ & $700.04(131.02)$ & $707.77(144.12)$ & $-0.162(0.871)$ \\
Maximum force of midfoot $(\mathrm{N})$ & $117.48(63.49)$ & $135.24(79.66)$ & $-0.541(0.588)$ \\
Maximum force of heel $(\mathrm{N})$ & $487.18(72.07)$ & $481.65(82.66)$ & $-0.298(0.766)$ \\
Maximum pressure of forefoot $\left(\mathrm{N} / \mathrm{cm}^{2}\right)$ & $50.94(9.70)$ & $46.04(8.32)$ & $-1.082(0.279)$ \\
Maximum pressure of midfoot $\left(\mathrm{N} / \mathrm{cm}^{2}\right)$ & $17.66(9.87)$ & $17.46(6.38)$ & $-0.433(0.665)$ \\
Maximum pressure of heel $\left(\mathrm{N} / \mathrm{cm}^{2}\right)$ & $39.78(7.05)$ & $38.29(9.44)$ & $-1.163(0.245)$ \\
\hline
\end{tabular}

Values are presented as mean (SD).

$\mathrm{HV}$ : halux valgus.

Table 5. Parameters in the right foot during gait between normal adults and HV adults

$(\mathrm{N}=40)$

\begin{tabular}{lccc}
\hline \multicolumn{1}{c}{ Parameters } & Normal adults $(\mathrm{n}=20)$ & HV adults $(\mathrm{n}=20)$ & $\mathrm{Z}(p)$ \\
\hline Foot rotation $\left({ }^{\circ}\right)$ & $7.56(4.92)$ & $8.15(5.31)$ & $-0.676(0.499)$ \\
Step length $(\mathrm{cm})$ & $61.79(6.56)$ & $59.52(4.98)$ & $-1.515(0.130)$ \\
Stance phase (\%) & $62.87(1.44)$ & $61.96(5.09)$ & $-0.325(0.745)$ \\
Load response (\%) & $12.79(1.71)$ & $13.03(1.22)$ & $-0.839(0.402)$ \\
Mid stance (\%) & $37.42(1.93)$ & $36.84(1.23)$ & $-1.353(0.176)$ \\
Pre-swing (\%) & $12.65(1.68)$ & $12.94(2.06)$ & $-0.298(0.766)$ \\
Swing phase $(\%)$ & $37.13(1.44)$ & $36.39(3.04)$ & $-0.216(0.829)$ \\
Step time $(\mathrm{s})$ & $0.52(0.05)$ & $0.54(0.05)$ & $-1.233(0.218)$ \\
Length of gait line (mm) & $212.99(15.32)$ & $208.52(17.87)$ & $-0.622(0.534)$ \\
Single support line (mm) & $115.80(10.55)$ & $112.29(8.25)$ & $-1.272(0.204)$ \\
Time change heel to forefoot $(\mathrm{s})$ & $0.26(0.05)$ & $0.24(0.05)$ & $-1.678(0.093)$ \\
Time change heel to forefoot $(\%)$ & $40.03(7.27)$ & $35.55(7.76)$ & $-2.191(0.028)$ \\
Maximum force of forefoot $(\mathrm{N})$ & $708.98(123.06)$ & $719.71(149.87)$ & $-0.081(0.935)$ \\
Maximum force of midfoot $(\mathrm{N})$ & $117.03(78.21)$ & $143.63(92.73)$ & $-1.245(0.213)$ \\
Maximum force of Heel $(\mathrm{N})$ & $473.90(73.59)$ & $478.44(73.88)$ & $-0.460(0.646)$ \\
Maximum pressure of forefoot $\left(\mathrm{N} / \mathrm{cm}^{2}\right)$ & $48.78(7.32)$ & $46.84(9.90)$ & $-0.730(0.465)$ \\
Maximum pressure of midfoot $\left(\mathrm{N} / \mathrm{cm}^{2}\right)$ & $15.04(7.06)$ & $16.84(5.68)$ & $-1.380(0.168)$ \\
Maximum pressure of heel $\left(\mathrm{N} / \mathrm{cm}^{2}\right)$ & $39.47(10.30)$ & $38.22(11.07)$ & $-0.676(0.499)$ \\
\hline
\end{tabular}

Values are presented as mean (SD).

HV: halux valgus.

\section{Discussion}

In this study, data were not distinguished by group in the simple linear regression analysis. In the assessment of the one-legged stance balance, the length of the major and minor axes significantly increased in the HV group compared with the normal group. Among gait parameters, time change from the heel to forefoot, expressed as percentage change, was 
Table 6. Equations for HVA of the left foot on the balance and gait parameters by simple regression analysis

\begin{tabular}{lllrrr}
\hline \multicolumn{1}{c}{ Parameters } & \multicolumn{1}{c}{ Regression equation } & $\mathrm{r}$ & $\mathrm{R}^{2}$ & $\beta$ & $\mathrm{F}(p)$ \\
\hline Time to change heel to forefoot $(\mathrm{s})$ & $0.302+(-0.002 \times \mathrm{HVA})$ & 0.336 & 0.113 & -0.336 & $4.841(0.034)$ \\
Time to change heel to forefoot $(\%)$ & $45.622+(-0.339 \times \mathrm{HVA})$ & 0.386 & 0.149 & -0.386 & $6.667(0.014)$ \\
Length of minor axis & $20.374+(0.424 \times \mathrm{HVA})$ & 0.408 & 0.166 & 0.408 & $7.579(0.009)$ \\
Length of major axis & $29.595+(1.221 \times \mathrm{HVA})$ & 0.350 & 0.123 & 0.350 & $5.310(0.027)$ \\
\hline
\end{tabular}

HVA: angle of halux valgus.

Table 7. Equations for HVA of the right foot on the balance and gait parameters by simple regression analysis

\begin{tabular}{lllrrr}
\hline \multicolumn{1}{c}{ Parameters } & \multicolumn{1}{c}{ Regression equation } & $\mathrm{r}$ & $\mathrm{R}^{2}$ & $\beta$ & $\mathrm{F}(p)$ \\
\hline Time to change heel to forefoot $(\%)$ & $43.421+(-0.349 \times \mathrm{HVA})$ & 0.329 & 0.108 & -0.329 & $4.614(0.038)$ \\
Length of minor axis & $24.161+(0.428 \times \mathrm{HVA})$ & 0.406 & 0.165 & 0.406 & $7.509(0.009)$ \\
\hline
\end{tabular}

HVA: angle of halux valgus.

significantly shorter in the HV group than in the normal group. In the linear regression analysis using HVA as an independent variable, the minor axis and time changes from heel to forefoot, expressed as percentage change, were significantly different between the groups. However, other balance and gait parameters were not significantly different between the groups.

A comparison of the two groups revealed no significant differences in most balance and gait parameters evaluated. This finding may be attributable to the young age of subjects (i.e., in their 20s) and their health status, as they did not complain of pain and other symptoms, according to the inclusion criteria. Nonetheless, a few balance and gait parameters were significantly different between the groups.

In the comparison of parameters used to assess one-legged stance balance, the length of the major and minor axes was significantly longer in the right and left feet in the HA group than in the normal group. During stance on the left leg, force $(\%)$ on the forefoot was significantly lower in the HA than in the normal group, whereas force (\%) on the back foot was significantly higher in the HA group than in the normal group. According to Cavanagh et al. [21], the plantar pressure distribution is located in the rear foot $(60 \%)$, midfoot $(8 \%)$, forefoot region ( $28 \%$ ), and toes (about $4 \%$ ), and the forefoot's peak pressure occurs under the second metatarsal head. Nyska et al. [22] stated that HV altered typical biomechanics, caused functional impairment of the great toe, and increased central metatarsal loading. Hutton and Dhanendran [23] suggested that changes in HV feet were accompanied with reduced weight-bearing function of the great toe, and reported increased peak pressure under the medial meta- tarsal head and load imposed on the central forefoot region as a typical pattern. In addition, Bryant et al. [24] reported that the peak pressure increased under the great toe region. However, Thomas and Barrington [6] claimed that the contact area of the great toe could be reduced due to the deformity and infection of the first metatarsal. Unlike results of previous studies, we found a significantly higher force distribution (\%) in the back foot and lower force distribution (\%) in the forefoot. This discrepancy can be explained by the young age of our subjects. However, this finding suggests the possibility that $\mathrm{HV}$ can cause distribution changes in plantar pressure; that is, toe deformity is closely associated with plantar pressure [19]. In contrast, this study found that HVA can help increase the path of the COP shift rather than plantar pressure, according to the linear regression analysis. Carvalho et al. [25] asserted that HV could affect sway during shifts of the COP to varying degrees, depending on the forefoot width and foot arch. Wen et al. [13] reported that contact time extends as motions increase loading on the lateral and medial rear foot regions. Although our study found different distribution patterns of plantar pressure in the $\mathrm{HV}$ feet compared with that reported in previous studies, such a difference implies that pressure could increase in some parts of the plantar relative to other parts of the plantar. As a result, COP bearing capability and shift distance may be affected more frequently in $\mathrm{HV}$.

In the comparison of gait parameters between the two groups, time change from the heel to forefoot, expressed as percentage change, was significantly shorter in the right and left feet in the HA group than in the normal group. In the assessment of left foot-related parameters, time change from 
the heel to forefoot, expressed as elapsed time, was also significantly shorter in the HA group than in the normal group. Canseco et al. [26] reported that foot-related disorders affect gait parameters. Nix et al. [27] reported that the experimental group with HA had changes in the weight-bearing pattern under the great toe and metatarsal head while walking. Menz and Morris [4] reported decreases in gait speed and phases in the HA group compared with the normal group. Deschamps et al. [1] stated that individuals with HA demonstrated similar gait pattern and time to those of healthy individuals during the entire stance and swing periods and that there was a difference in plantar pressure distribution during walking between the groups. According to Wen et al. [13], the tendency of increasing weight bearing at the midfoot, once started in the early stance phase of gait, eventually delays weight transfer from the medial side to lateral side of the foot. In the present study, we found no differences in the entire stance period as expressed in seconds and as a percentage. However, time change from the heel to forefoot was shorter, which indicates a shorter duration of weight bearing at the forefoot. When walking is repeated with this parameter, the forefoot's pressure will aggregate, increasing the risk of cumulative damage to the foot.

The plantar pressure measurement serves as an indicator of foot and ankle functions during walking and other functional activities. The size and pattern of pressure distribution at the plantar surface depends on the structural and functional status of the foot and ground state. Abnormal foot pressures are associated with not only pain but also foot deformity [28].

This study has some limitations. Pressure distribution parameters were used in the gait analysis of the forefoot as a whole rather than the hallux region; thus, further analysis of the forefoot segments is required in future studies. Given that only young subjects in their 20s participated in this study, a larger study sample that includes older adults is necessary in further studies.

In conclusion, the present study identified the relationship of HVA with balance and gait performance in young adults by measuring the HVA and analyzing static and dynamic parameters obtained from the one-legged stance and a 6-m walking test. Given that walking is a repetitive activity, young adults with $\mathrm{HV}$ could potentially develop disease or cumulative damage to the feet in later stages of life. Future studies are needed to address this possibility through accurate measurements and analysis.

\section{Conflict of Interest}

The authors declared no potential conflicts of interest with respect to the authorship and/or publication of this article.

\section{References}

1. Deschamps K, Birch I, Desloovere K, Matricali GA. The impact of hallux valgus on foot kinematics: a cross-sectional, comparative study. Gait Posture 2010;32:102-6.

2. Glasoe WM, Nuckley DJ, Ludewig PM. Hallux valgus and the first metatarsal arch segment: a theoretical biomechanical perspective. Phys Ther 2010;90:110-20.

3. Roddy E, Zhang W, Doherty M. Prevalence and associations of hallux valgus in a primary care population. Arthritis Rheum 2008; 59:857-62.

4. Menz HB, Morris ME. Footwear characteristics and foot problems in older people. Gerontology 2005;51:346-51.

5. Nguyen US, Hillstrom HJ, Li W, Dufour AB, Kiel DP, ProcterGray E, et al. Factors associated with hallux valgus in a population-based study of older women and men: the MOBILIZE Boston Study. Osteoarthritis Cartilage 2010;18:41-6.

6. Thomas S, Barrington R. Hallux valgus. Orthop Trauma 2003; 17:299-307.

7. Lin JS, Bustillo J. Surgical treatment of hallux valgus: a review. Curr Opin Orthop 2007;18:112-7.

8. Mann RA, Coughlin MJ. Adult hallux valgus. In: Coughlin MJ, Mann RA, editors. Surgery of the foot and ankle. 7th ed. St. Louis: Mosby; 1999. p. 150

9. Piqué-Vidal C, Vila J. A geometric analysis of hallux valgus: correlation with clinical assessment of severity. J Foot Ankle Res 2009;2:15.

10. Stewart S, Ellis R, Heath M, Rome K. Ultrasonic evaluation of the abductor hallucis muscle in hallux valgus: a cross-sectional observational study. BMC Musculoskelet Disord 2013;14:45.

11. Suzuki J, Tanaka Y, Takaoka T, Kadono K, Takakura Y. Axial radiographic evaluation in hallux valgus: evaluation of the transverse arch in the forefoot. J Orthop Sci 2004;9:446-51.

12. Steinberg N, Finestone A, Noff M, Zeev A, Dar G. Relationship between lower extremity alignment and hallux valgus in women. Foot Ankle Int 2013;34:824-31.

13. Wen J, Ding Q, Yu Z, Sun W, Wang Q, Wei K. Adaptive changes of foot pressure in hallux valgus patients. Gait Posture 2012;36: 344-9.

14. Nishimura A, Ito N, Nakazora S, Kato K, Ogura T, Sudo A. Does hallux valgus impair physical function? BMC Musculoskelet Disord 2018;19:174.

15. Ferrari J, Hopkinson DA, Linney AD. Size and shape differences between male and female foot bones: is the female foot predisposed to hallux abducto valgus deformity? J Am Podiatr Med Assoc 2004;94:434-52.

16. Schuh R, Hofstaetter SG, Adams SB Jr, Pichler F, Kristen KH, Trnka HJ. Rehabilitation after hallux valgus surgery: importance of physical therapy to restore weight bearing of the first ray during the stance phase. Phys Ther 2009;89:934-45. 
17. Martínez-Nova A, Sánchez-Rodríguez R, Pérez-Soriano P, Llana-Belloch S, Leal-Muro A, Pedrera-Zamorano JD. Plantar pressures determinants in mild Hallux Valgus. Gait Posture 2010;32:425-7.

18. Bryant A. Tinley P. Singer K. Radiographic measurements and plantar pressure distribution in normal, hallux valgus and hallux limitus feet. Foot 2000;10:18-22.

19. Mickle KJ, Munro BJ, Lord SR, Menz HB, Steele JR. Gait, balance and plantar pressures in older people with toe deformities. Gait Posture 2011;34:347-51.

20. Srivastava S, Chockalingam N, El Fakhri T. Radiographic angles in hallux valgus: comparison between manual and computer-assisted measurements. J Foot Ankle Surg 2010;49:523-8.

21. Cavanagh PR, Morag E, Boulton AJ, Young MJ, Deffner KT, Pammer SE. The relationship of static foot structure to dynamic foot function. J Biomech 1997;30:243-50.

22. Nyska M, Liberson A, McCabe C, Linge K, Klenerman L. Plantar foot pressure distribution in patients with Hallux valgus treated by distal soft tissue procedure and proximal metatarsal osteotomy. Foot Ankle Surg 1998;4:35-41.
23. Hutton WC, Dhanendran M. The mechanics of normal and hallux valgus feet--a quantitative study. Clin Orthop Relat Res 1981;(157):7-13.

24. Bryant A, Tinley P, Singer K. Plantar pressure distribution in normal, hallux valgus and hallux limitus feet. Foot 1999;9:115-9.

25. Carvalho CE, da Silva RA, Gil AW, Oliveira MR, Nascimento JA, Pires-Oliveira DA. Relationship between foot posture measurements and force platform parameters during two balance tasks in older and younger subjects. J Phys Ther Sci 2015;27: 705-10.

26. Canseco K, Long J, Marks R, Khazzam M, Harris G. Quantitative characterization of gait kinematics in patients with hallux rigidus using the Milwaukee foot model. J Orthop Res 2008;26: 419-27.

27. Nix SE, Vicenzino BT, Collins NJ, Smith MD. Gait parameters associated with hallux valgus: a systematic review. J Foot Ankle Res 2013;6:9.

28. Orlin MN, McPoil TG. Plantar pressure assessment. Phys Ther 2000;80:399-409. 